\title{
Study on Environmental Stress Situation in the Blue Jiaodong Peninsula Economic Zone
}

\author{
Chongmei Wang \\ School of administration, Shandong Institute of Business and Technology, Yantai, 264005, China \\ Shandong collaborative innovation center of energy economy, Yantai, 264005, China
}

Keywords: decoupling index, environment, Jiaodong peninsula.

\begin{abstract}
Now, the problem of energy and environment has become a major problem in Jiaodong Peninsula area, affecting local development and future. Energy and the environment have become the bottleneck of economic development in Jiaodong Peninsula. This paper selected a typical city of the Jiaodong Peninsula, Qingdao, Yantai and Weihai as the sample, which studied the relationship between the environmental pressure and economic growth by "decoupling" index; and collected data of energy consumption, environmental pollution and economic development in 2000--2010 during 10 years. We can come to conclude that it is a relatively decoupling status between the environment pressure and economic development in the Jiaodong Peninsula which has been facing seriously environment pressure, especially after 2007, the regional economic development has faced increasingly pressure.
\end{abstract}

\section{Introduction}

We can use decoupling ratio (decoupling ratio) form to do quantitative description of environmental pressure and economic growth relationship. Decoupling ratio is required to examine variables between index ratio, the molecule and the denominator is on behalf of environment pressure and a driving force. Typically to use GDP as a reflection of the level of economic development indicators, sometimes it uses population growth or other indicators. Environmental stress growth indicators did not form a unified view. In many cases the resource consumption and waste emissions is measured by the index. This paper mainly undertake a large number of data collection and field investigation, due to environmental statistics for the first time in 2004, in the 2004 statistical yearbook of Shandong province could not find the resources and environment data, therefore, to the blue Jiaodong Peninsula Economic Zone environmental stress situation analysis this article is limited to the form data after 2004 year. In this respect, but also fully embodies the nearly six years, Shandong province for environment resource increasingly attention. Subject analysis of the Jiaodong peninsula economic growth and energy consumption, economic growth and SO2, COD, industrial dust and waste, emissions, through the analysis of the index, which are as far as possible to evaluate economic growth and environment pressure.

\section{Economic Development and energy consumption gross decoupling}

As the GDP and the energy consumption quantity of different levels, the data can be converted into index form as the comparison analysis, the method is to base year data for 100, other years data with the base year for ratio calculation, in 2000 as an example the specific calculation formula (1) shown below.

$N_{n}=\frac{D_{n}}{D_{2000}} \times 100$

$D_{2000}$ : The original 2000 data, $D_{n}$ : The $\mathrm{N}$ raw data, $N_{n}$ : The $\mathrm{n}$ index data

In order to response the relation between Jiaodong Peninsula GDP and energy consumption, eliminating factors due to price increasing and the impact on GDP in this period. Based on GDP number and price of 2000 year as the base point, we recalculate over others GDP. 
Diagram 2 is based on the table 2 sixth columns and the twelfth column, because the statistical yearbook data over the GDP is used on current prices, in order to eliminate price factors, the 2000 GDP value as 1 , and then multiplied by the rate of economic growth; obtain the comparable price GDP growth rate.

According to diagram 2, Jiaodong peninsula economic development and energy situation is roughly divided into two stages. Before of 2005 year, increasing of energy consumption is the same with GDP growth condition. In the diagram they are basically in coincidence, after 2005, GDP has presented the large scale growth, far exceeding the energy consumption growth. From the picture, we can have clearly seen relative decoupling conditions in the Jiaodong peninsula economic growth and energy consumption after 2005, from 2000 to 2004, in the double hook stage, the future environmental pressure is very heavy.

Table 2-1 GDP and energy consumption relationship in 2000 for the base period price

\begin{tabular}{|c|c|c|c|c|c|c|c|c|c|c|}
\hline \multicolumn{5}{|c|}{ GDP ( billion ) in 2000 as the base year } & \multicolumn{4}{|c|}{ GDP growth index } & \multirow{2}{*}{$\begin{array}{c}\text { Energy } \\
\text { consumption } \\
\text { elasticity } \\
\text { coefficient }\end{array}$} & \multirow{2}{*}{$\begin{array}{c}\text { Energy } \\
\text { consumption } \\
\text { index }\end{array}$} \\
\hline \multicolumn{2}{|c|}{$\begin{array}{l}\text { Jiaodong } \\
\text { Peninsula }\end{array}$} & Qingdao & Yantai & Weihai & $\begin{array}{l}\text { Jiaodong } \\
\text { Peninsula }\end{array}$ & Qingdao & Yantai & Weihai & & \\
\hline 2000 & 2592.09 & 1151.2 & 880 & 560.89 & 1.0 & 1.0 & 1.0 & 1.0 & & 1.0 \\
\hline 2001 & 2923.1 & 1316 & 980 & 627.1 & 1.13 & 1.14 & 1.11 & 1.12 & 1.03 & 1.10 \\
\hline 2002 & 3336.7 & 1518.2 & 1115 & 703.5 & 1.29 & 1.32 & 1.27 & 1.25 & 1.56 & 1.30 \\
\hline 2003 & 3932.02 & 1780.3 & 1316 & 836.02 & 1.52 & 1.55 & 1.50 & 1.49 & 1.36 & 1.54 \\
\hline 2004 & 4811.61 & 2163.8 & 1639 & 1008.81 & 1.86 & 1.88 & 1.86 & 1.80 & 1.39 & 1.89 \\
\hline 2005 & 5877.81 & 2695.58 & 2012.46 & 1169.77 & 2.27 & 2.34 & 2.29 & 2.09 & 1.32 & 2.24 \\
\hline 2006 & 6980.86 & 3206.58 & 2405.75 & 1368.53 & 2.69 & 2.79 & 2.73 & 2.44 & 0.73 & 2.49 \\
\hline 2007 & 8249.93 & 3786.52 & 2879.96 & 1583.45 & 3.18 & 3.33 & 3.27 & 2.82 & 0.64 & 2.71 \\
\hline 2008 & 9650.72 & 4436.18 & 3434.19 & 1780.35 & 3.72 & 3.85 & 3.90 & 3.17 & 0.38 & 2.82 \\
\hline 2009 & 10588.37 & 4890.33 & 3728.68 & 1969.36 & 4.08 & 4.25 & 4.23 & 3.51 & & \\
\hline
\end{tabular}

Data source: 2000-2009 Qingdao, Yantai, Weihai statistical yearbook

Table 2 Jiaodong Peninsula main city decoupling index 


\begin{tabular}{|c|c|c|c|c|}
\hline & \multicolumn{3}{|c|}{ Decoupling index } \\
\hline Particular year & Jiaodong Peninsula & Qingdao & Yantai & Weihai \\
\hline 2000 & 1.0 & 1.0 & 1.0 & 0.98 \\
\hline 2001 & 0.97 & 0.96 & 0.99 & 1.04 \\
\hline 2002 & 1.007 & 0.98 & 1.02 & 1.03 \\
\hline 2003 & 1.013 & 0.9 & 1.03 & 1.05 \\
\hline 2004 & 1.016 & 1.005 & 0.02 & 1.07 \\
\hline 2005 & 0.99 & 0.96 & 0.91 & 1.02 \\
\hline 2006 & 0.93 & 0.89 & 0.82 & 0.96 \\
\hline 2007 & 0.85 & 0.81 & 0.72 & 0.88 \\
\hline
\end{tabular}

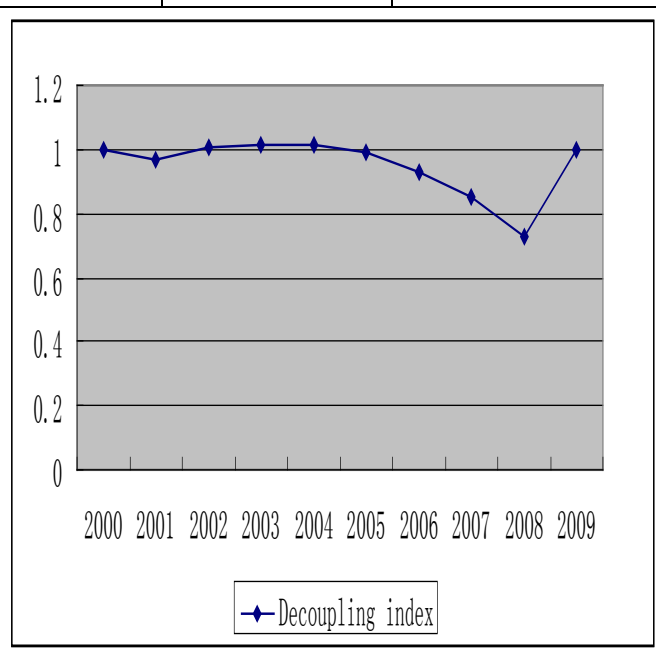

Figure 1 blue Jiaodong Peninsula Economic Zone Economic Development and energy consumption relationship

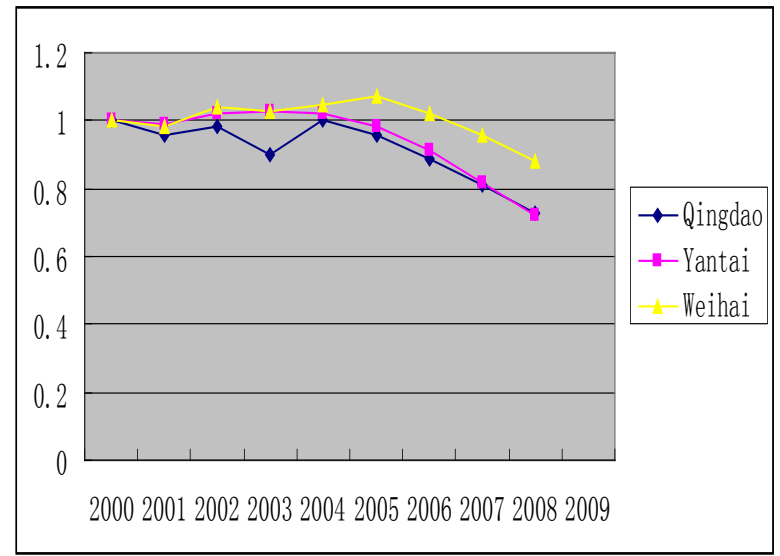

Figure 2 Jiaodong Peninsula, Qingdao, Yantai, Weihai, decoupling index of economic growth and energy consumption

\section{Conclusions}


From the diagram 2, we can see which environmental pressure and economic growth relationship has been in good condition in Qingdao for 8 years; Decoupling index has been less than 1 except for 2004, as relatively decoupling condition, namely economic growth rate is greater than the energy consumption rate. Weihai, relatively speaking, is more serious, which economic growth and energy consumption is in the double hook state, the energy consumption is relatively large, the strength, elasticity coefficient is relatively large; the condition of Yantai is in between the two, from 2002 to 2004 were slightly complex hook status.

\section{Acknowledgements}

Shandong collaborative innovation center of energy economy (2014 SDXT011)

\section{References:}

[1] OECD.OECD-China seminar on environmental indicators pro ceedings R. Diagram 2 Jiaodong Peninsula, Qingdao, Yantai, Weihai, decoupling index of economic growth and energy consumption

[2] Paris: OECD, 2005.

[3] OECD. Indicators to Measure Decoupling of Environmental Pressure from Economic

[4] Growth.2002.

[5] http://www.olis.oecd.org/olis/2002doc.nsf/LinkTo/sg-sd (2002) 1-final. 2008-9-26.

[6] 2000-2009 Yantai statistical yearbook.

[7] 2000-2009 Qingdao statistical yearbook.

[8] 2000-2009 Weihai statistical yearbook. 